\title{
STUDY TO ASSESS THE KNOWLEDGE \& AWARENESS REGARDING EYE DONATION AMONG STUDENTS OF CIMS BILASPUR (C.G.)
}

\section{Community Medicine}

Dr. Vijay Kumar Manwani

Associate Professor, Department Of Community Medicine CIMS, Bilaspur.

\section{Dr. Bharat}

Bhushan Khurse*

Surgical Oncologist, CIMS, Bilaspur. *corresponding Author

Dr Shakuntala Jitpure

Prof. \& Head, Department Of Community Medicine CIMS, Bilaspur.

\section{ABSTRACT}

Background-Eye donation is an act of donating ones eye after his/her death. it is an act of charity,purely for the benefit of the society and is totally voluntary. age or systemic illness such as diabetes or hypertension, heart disease $\backslash$,kidney disease is not barrier for eye donation.. eye disease are a significant cause of visual impairment and blindness in the developing world.approximately 18.7 million people are blind in india and 1,90,000 are blind from bilateral corneal disease.For such people corneal transplantation helps in restoring their sight. According to the eye bank association of india the current cornea procurement rate in india is 22,000 per year.Programme and activities conducted across the country to impart the significance of eye donation and its useful to visual impaired people.

Objectives- 1.To assess sociodemographic profile of the students.2.To assess the knowledge \& awareness regarding eye donation among study subject.

Methodology-Study Subject;-Medical student CIMS college Bilaspur.

Type Of Study :-Observational Cross sectional study.

Study Area :- CIMS medical college

Study Duration:- July 2017 to December 2017

Sample Size :- 100medical students in CIMS medical college Bilaspur(C.G)

Study Tools :- Pre designed questionnaires

Results:- In the present study, there was nearly $46 \%$ male and $54 \%$ female. $100 \%$ of the participants had heard about eye donation. The commonest source of knowledge on eye donation, $\operatorname{Dr}(32 \%)$ followed by TV $(25 \%)$. Friends $(20 \%)$. Majority $(63 \%)$ of participants had correct knowledge that eye should be removed from dead donor within 6 hours. $80 \%$ of the participants replied eye donation is done by all age group people.

Conclusion:- Majority (63\%) of participant had correct knowledge regarding eye donation. Majority (79\%) of the students have willingness regarding eye donation.

\section{KEYWORDS}

Knowledge, Eye Donation, Medical Students,awareness

\section{INTRODUCTION}

Eye donation is an act of donating ones eye after his/her death. it is an act of charity,purely for the benefit of the society and is totally voluntary. Approximately 18.7 million people are blind in india and $1,90,000$ are blind from bilateral corneal disease[1].for such people corneal transplantation helps in restoring their sight. According to the eye bank association of india the current cornea procurement rate in india is 22,000 per year[2,3].

The Andhra Pradesh eye disease study reported the prevalence of corneal blindness at $0.13 \%$ constitution , $9 \%$ of all blindness. APEDS also suggested a significance burden of corneal blindness in the rural population of Andhra Pradesh of which $95 \%$ of avoidable[1].1,90,000 are blind from bilateral corneal disease, every year another 20,000 join the list.[2].The late Dr. Nuthian started the very first eye bank in india and he successfully perform the first corneal transplantation in 1948.[3]

According to eye bank association of india the current corneal procurement rate in india is 20,000 per year it is estimated that a significant proportion of doner corneas are unsuitable for corneal transplantation.[4]. Even after more than 50 yrs patients waiting for corneal transplant constituted a considerable darklog which continue to grow.[5]

This study was carried out to assess the knowledge \& awareness regarding eye donation among second year students of CIMS Medical College Bilaspur.

\section{Aim}

To assess knowledge \& willingness regarding eye donation and eye banking among students of CIMS medical college.

\section{Objectives}

1. To assess sociodemographic profile of students

2. To assess the knowledge and awareness regarding eye donation among study subject.

\section{Material and Method}

Study Participants ;-Medical student CIMS college Bilaspur.

Type Of Study:-Observational Cross sectional study.

Study Settings :- CIMS medical college

Study Duration:- July 2017 to December 2017

Sample Size :-

100 medical students in CIMS medical college Bilaspur(C.G)

Study Tools :- Pre designed Pretested questionnaires.

Inclusion Criterion:- Those who are giving consent for the study.

Exclusion Criterion:-

Those who are not giving consent for the study or absent.

\section{Methodology:-}

Our study was a cross sectional descriptive study to find out the knowledge of eye donation in second year medical students CIMS college bilaspur. Total student participated were 100. Questionnaire was pre designed and tested and informed consent was taken from the subject before the study. on the day of study instruction were given to the student before filling the proforma how to fill, half hour was given after that proforma was collected and data was compiled in MS-excel and was checked for the completeness for further analysis using the Epi-Info software package, Version 6.04 .

Observations and Results

Table Number 1:-Gender distribution of medical students..

\begin{tabular}{|l|l|l|}
\hline Sex & Number & Percentage(\%) \\
\hline Male & $\mathbf{4 6}$ & $\mathbf{4 6 \%}$ \\
\hline Female & 54 & $\mathbf{5 4 \%}$ \\
\hline Total & 100 & $\mathbf{1 0 0 \%}$ \\
\hline
\end{tabular}

Inference:-A total of 100 students participated in the study from which $46 \%$ were male and $54 \%$ female. 
Table Number 2:-educational status of mother of medical student.

\begin{tabular}{|l|l|l|}
\hline Educational status & Number & Percentage (\%) \\
\hline Illiterate & $\mathbf{3}$ & $\mathbf{3}$ \\
\hline Primary & $\mathbf{1 8}$ & $\mathbf{1 8}$ \\
\hline High School & $\mathbf{2 0}$ & $\mathbf{2 0}$ \\
\hline Higher secondary & $\mathbf{2 2}$ & $\mathbf{2 2}$ \\
\hline Graduate \& above & $\mathbf{3 7}$ & $\mathbf{3 7}$ \\
\hline Total & $\mathbf{1 0 0}$ & $\mathbf{1 0 0 \%}$ \\
\hline
\end{tabular}

Inference:- From the above data percentage of maximum graduate $\&$ above mother found to be $37 \%$, and minimum percentage of illiterate mother found to be $3 \%$.

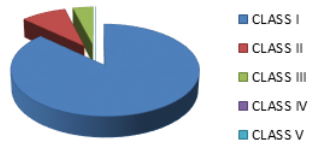

Figure No. 1-: Socio Economic status of medical students.

Table number 3:-Knowledge regarding who can donate eyes among medical students

\begin{tabular}{|l|l|l|}
\hline Person & Number & Percentage \\
\hline Male & $\mathbf{1}$ & $\mathbf{1}$ \\
\hline Female & $\mathbf{1}$ & $\mathbf{1}$ \\
\hline Children & $\mathbf{0}$ & $\mathbf{0}$ \\
\hline Healthy person & $\mathbf{1 7}$ & $\mathbf{1 7}$ \\
\hline other than eye disease & $\mathbf{2}$ & $\mathbf{2}$ \\
\hline All of the above & $\mathbf{7 9}$ & $\mathbf{7 9}$ \\
\hline
\end{tabular}

Inference :-this table show that $79 \%$ of total participant think that all of the person listed in above options can donate eye.

Table number 4:-knowledge regarding age at which eye can be donated.

\begin{tabular}{|l|l|l|}
\hline Age & Number & Percentage \\
\hline 30 years & $\mathbf{1 2}$ & $\mathbf{1 2}$ \\
\hline 60 years & $\mathbf{8}$ & $\mathbf{8}$ \\
\hline All ages & $\mathbf{8 0}$ & $\mathbf{8 0}$ \\
\hline Total & $\mathbf{1 0 0}$ & $\mathbf{1 0 0} \%$ \\
\hline
\end{tabular}

Inference:-From the above table we found that $80 \%$ of students thinks that eye can be donated at all ages.

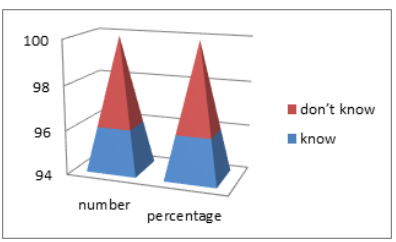

Figure No. 2-: knowledge regarding Centre for registration of eye donation

Inference:-From the above diagram we find $96 \%$ students know the center for registration of eye donation.

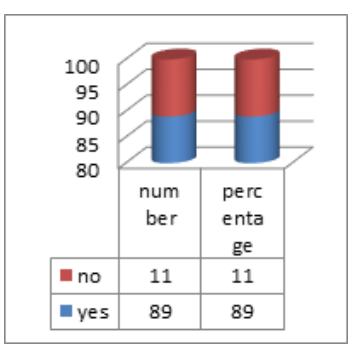

Figure No. 3:-knowledge regarding willful eye donation before death.

Inference:-From the above diagram we found that $89 \%$ of the students know that the eye can be donated willfully before death.

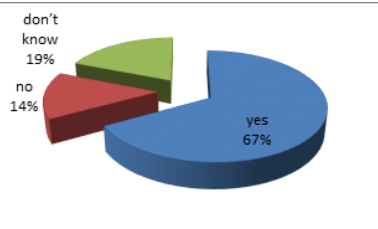

Figure No. 4 :-knowledge regarding consent for eye donation by family member of dying relative

Inference:-From the above diagram we found that $67 \%$ of the students know that the consent for eye donation can be given by family member after dying of relative.

Table number 5:-knowledge regarding which part of eye is donated.

\begin{tabular}{|l|l|l|}
\hline Part & Number & Percentage \\
\hline Cornea & $\mathbf{9 6}$ & $\mathbf{9 6}$ \\
\hline Lens & $\mathbf{0}$ & $\mathbf{0}$ \\
\hline Iris & $\mathbf{0}$ & $\mathbf{0}$ \\
\hline Whole eye & $\mathbf{2}$ & $\mathbf{2}$ \\
\hline Don't know & $\mathbf{2}$ & $\mathbf{2}$ \\
\hline Total & $\mathbf{1 0 0}$ & $\mathbf{1 0 0 \%}$ \\
\hline
\end{tabular}

Inference:-From the above table we found that $96 \%$ of the students know that CORNEA is the part which is donate during eye donation.

Table number 6:-knowledge regarding screening before eye donation.

\begin{tabular}{|l|l|l|}
\hline Knowledge & Number & Percentage \\
\hline Yes & $\mathbf{6 0}$ & $\mathbf{6 0}$ \\
\hline No & $\mathbf{1 7}$ & $\mathbf{1 7}$ \\
\hline Don't know & $\mathbf{2 3}$ & $\mathbf{2 3}$ \\
\hline Total & $\mathbf{1 0 0}$ & $\mathbf{1 0 0} \%$ \\
\hline
\end{tabular}

Inference:- From the above table we found that $60 \%$ of the students thinks that screening process is done before eye donation.

Table number 7:-knowledge regarding how long eye can be stored for donation.

\begin{tabular}{|l|l|l|}
\hline Duration & Number & Percentage \\
\hline Up to 14 days & $\mathbf{5 1}$ & $\mathbf{5 1}$ \\
\hline Up to 7 days & $\mathbf{8}$ & $\mathbf{8}$ \\
\hline Up to 3 days & $\mathbf{2}$ & $\mathbf{2}$ \\
\hline Up to 1 day & $\mathbf{2 1}$ & $\mathbf{2 1}$ \\
\hline Don't know & $\mathbf{1 8}$ & $\mathbf{1 8}$ \\
\hline Total & $\mathbf{1 0 0}$ & $\mathbf{1 0 0} \%$ \\
\hline
\end{tabular}

Inference:- From the above table we found that $51 \%$ of the students thinks that eye can be stored for upto 14 days and $2 \%$ of students thinks that the eye can be stored for upto 3 days for eye donation.

Table number 8:-knowledge regarding maximum time the eye should be removed from dead body

\begin{tabular}{|l|l|l|}
\hline Duration & Number & Percentage \\
\hline 2 hours & $\mathbf{1 3}$ & $\mathbf{1 3}$ \\
\hline 4 hours & $\mathbf{1 2}$ & $\mathbf{1 2}$ \\
\hline 6 hours & $\mathbf{6 3}$ & $\mathbf{6 3}$ \\
\hline 10 hours & $\mathbf{3}$ & $\mathbf{3}$ \\
\hline Don't know & $\mathbf{9}$ & $\mathbf{9}$ \\
\hline Total & $\mathbf{1 0 0}$ & $\mathbf{1 0 0} \%$ \\
\hline
\end{tabular}

Inference:- From the above table we found that $63 \%$ of the students thinks that eye should be removed from dead body before 6 hours and $3 \%$ of the students thinks that eye should be removed from dead body before 10 hours.

Table number 9:-from where they get to know about eye donation

\begin{tabular}{|l|l|l|}
\hline Source & Number & Percentage \\
\hline TV & $\mathbf{2 5}$ & $\mathbf{2 5}$ \\
\hline Newspaper & $\mathbf{8}$ & $\mathbf{8}$ \\
\hline Radio & $\mathbf{3}$ & $\mathbf{3}$ \\
\hline Friends & $\mathbf{2 0}$ & $\mathbf{2 0}$ \\
\hline Doctor & $\mathbf{3 2}$ & $\mathbf{3 2}$ \\
\hline Others & $\mathbf{1 2}$ & $\mathbf{1 2}$ \\
\hline Total & $\mathbf{1 0 0}$ & $\mathbf{1 0 0} \%$ \\
\hline
\end{tabular}

Inference:- From the above table we found that $32 \%$ of the student 
know about eye donation from Drs and 3\% of the students know from Radio.

Table Number 10:-Students willing for eye donation

\begin{tabular}{|l|l|l|}
\hline Willingness & Number & Percentage \\
\hline Yes & $\mathbf{7 9}$ & $\mathbf{7 9}$ \\
\hline No & $\mathbf{2 1}$ & $\mathbf{2 1}$ \\
\hline Total & $\mathbf{1 0 0}$ & $\mathbf{1 0 0} \%$ \\
\hline
\end{tabular}

Inference:-From the above table we found $79 \%$ of students were willing for eye donation.

\section{DISCUSSION}

Medical students can directly communicate and counsel larger sections of the society that give a push up to the eye donation movement in India

In the present study, there was nearly $46 \%$ male and $54 \%$ female, but a study in Bangalore showed that almost male to female ratio in the nursing course was equal $(56.4 \%$ male and $43.6 \%$ female)

In the present study, $100 \%$ of the participants had heard about eye donation. A study among nursing students in Bhopal showed $98 \%$ of the total students had heard about eye donation.A study among 1525 students of North Kolkata showed that $81 \%$ of students had knowledge of eye donation.

In present study the commonest source of knowledge on eye donation, $\operatorname{Dr}(32 \%)$ followed by TV( $25 \%)$, Friends (20\%). A study conducted in Tirupati, showed that newspaper $(64.75 \%)$ was the main source of information on eye donation for majority of students followed by Doctors (60.75\%), Television (51.25\%) and health workers (25.25\%) which are higher than present study .A study conducted among university students in Kuala lumpur, Malaysia, nursing students in Bongalore and Auragangabad showed Television as a main source of information for eye donation.

In the present study, majority $(63 \%)$ of participants had correct knowledge that eye should be removed from dead donor within 6 hours. A study conducted among the students in Bhopal showed that $21.7 \%$ of nursing students had correct knowledge that. A study conducted in North Kolkata, India showed that only $32.1 \%$ of the participants knew that the ideal time.

In our study, $80 \%$ of the participants replied eye donation is done by all age group people. A study conducted in Hubli, Karnataka, $69 \%$ of the participants believed that there was no age limit for eye donation.In our study, majority $(79 \%)$ participants willing to donate their eyes. In most of the studies $34.42 \%$ to $46 \%$ of the participants were willing to donate their eyes.

\section{CONCLUSION}

- We observed that among this cases $46 \%$ were male and $54 \%$ were female

- We observed that $100 \%$ of the participants had heard about eye donation.

- We observed that the commonest source of knowledge on eye donation by doctor $32 \%$,TV $25 \%$, Friends $20 \%$.

- We observed that majority $63 \%$ of participant had correct knowledge that the eye should be removed from dead with in 6 hours.

- We observed that $80 \%$ of participants replied eye donation is done by all age group people.

- We observed that majority $79 \%$ participants willing to donate their eye.

\section{REFERENCES}

1. Awareness and perception regarding eye donation in students of a nursing college in banglore. (http://www.scopemed.org/?mno=160647)

Eye donation among undergraduate medical student, tirupati. (http://www.ncbi.nlm.nih.gov/pmc/articles/pmc2781118/)

3. A study on perception about eye health care and promoting factor for eye donation among medical students from a teriary care teaching hospital.(www.iaimjournal.com)

To study awareness and willingness of eye donation among paramedical workers ( h t t p : / / j c or. i n/article.as p ? i s s n = 2320 $3897 ;$ year $=2015 ;$ volume $=3 ;$ issue $=2 ;$ spage $=95 ;$ epageaulast $=$ magdum $)$ 5. Medical students perception on eye donation in delhi. (http://wwwijo.in/article.asp)

6. Thylefors B, Negrel AD, Pararajasegaram R, Dadzie KY. Global data on blindness. Bull World Health Organ 1995; 73; 115-21.

Whitcher JP, Srinivasan M, Upadhyay MP. Corneal blindness: a global perspective. Bull World Health Organ 2001; 79:214-21.

8. Dr. R. Jose,Present status of the National Programme for Control of Blindness in
India;Community Eye Health Journal,2008,65:S 103-105.

9. M K Bharti,S C Reddy,I Tajunisah, N A M Ali, M Med J Malaysia Voln64 No1 March 2009,41-45

10. Thomas R, Paul P, Rao GN, Muliyil JP, Mathai A. Surv Ophthalmol. 2005 JanFeb;50(1):85-101

11. Dhaliwal U. Indian J Ophthalmol. 2002 Dec; 50(4):358-9.

12. Gupta A, Jain S, Jain T, Gupta K, Indian J Community Med. 2009 Apr; 34(2): 122-5.

13. Singh MM, Rahi M, Pagare D, Ingle GK. Indian J Ophthalmol. 2007 Jan-Feb; 55(1):4953

14. Manjunath S Nekar, Laxmikant Lokare*, Sunil A Gokhale, Maneesha Godbole, S Y Mulkipatil,Awareness of eye donation among college students of Hubli city,Karnataka.International Journal of Biomedical Research 2012,Vol 3, No. 4 , 201-204

15. John P. Whitcher, 1 M. Srinivasan,2 \& Madan P. Upadhyay. Corneal blindness: a global perspective Bulletin of the World Health Organization, 2001, 79 (3);214

16. Ind i a h s largest blind population. Ava i lable http://articles.timesofindia.indiatimes.com/2007-10- 11/india/27977420_1_avoidableblindnes. Accessed on 23 December, 2017 